\title{
The Mouse Aire Gene: Comparative Genomic Sequencing, Gene Organization, and Expression
}

\author{
Karin Blechschmidt, ${ }^{1}$ Michal Schweiger, ${ }^{2}$ Karin Wertz, ${ }^{3}$ Richard Poulson, ${ }^{4}$ \\ Hoang-My Christensen, ${ }^{2}$ Andre Rosenthal, ${ }^{1}$ Hans Lehrach, ${ }^{2}$ \\ and Marie-Laure Yaspo ${ }^{2,5}$ \\ ${ }^{1}$ Institute of Molecular Biotechnology, Department of Genome Analysis, D-07745 Jena, Germany; ${ }^{2}$ Max-Planck Institute \\ for Molecular Genetics, D-14195 Berlin-Dahlem, Germany; ${ }^{3}$ Max-Planck Institute for Immunobiology, D-79108 Freiburg, \\ Germany; ${ }^{4}$ Imperial Cancer Research Fund; Histopathology Unit, London, UK
}

\begin{abstract}
Mutations in the human AIRE gene (hAIRE) result in the development of an autoimmune disease named APECED (ạutoimmune polyendocrinopathy çandidiasis ectodermal dystrophy; OMIM 240300). Previously, we have cloned hAIRE and shown that it codes for a putative transcription-associated factor. Here we report the cloning and characterization of Aire, the murine ortholog of hAIRE. Comparative genomic sequencing revealed that the structure of the AIRE gene is highly conserved between human and mouse. The conceptual proteins share $73 \%$ homology and feature the same typical functional domains in both species. RT-PCR analysis detected three splice variant isoforms in various mouse tissues, and interestingly one isoform was conserved in human, suggesting potential biological relevance of this product. In situ hybridization on mouse and human histological sections showed that AIRE expression pattern was mainly restricted to a few cells in the thymus, calling for a tissue-specific function of the gene product.
\end{abstract}

There is a wide range of human autoimmune diseases, but the molecular background of autoimmunity remains poorly understood (Ollier 1992). Despite the identification of a number of genetic susceptibility factors, the etiology of most autoimmune diseases remains elusive. In this context, the study of autoimmune conditions with Mendelian inheritance could provide a boost for unraveling pathogenic pathways involved in human autoimmunity.

Autoimmune polyendocrinopathy candidiasis ectodermal dystrophy [APECED, Online Mendelian Inheritance in Man (OMIM) 240300] is an autosomal recessive disease resulting in a variable combination of failure of the parathyroid glands, adrenal cortex, gonads, and pancreatic $\beta$ cells (Ahonen 1985). Ectodermal dystrophies, vitiligo, and chronic mucocutaneous candidiasis are also frequently observed among APECED patients (Ahonen et al. 1990; Perheentupa 1996). APECED is a rare disease particularly enriched in genetic isolates, such as the Finnish population, Iranian Jews, and Sardinians (Ahonen 1985; Zlotogora and Shapiro 1992; Clemente et al. 1997). After demonstration of genetic linkage and locus homogeneity on chromosome 21q22.3 (Aaltonen et al. 1994; Bjorses et al. 1996), the APECED gene was cloned and called AIRE for autoimmune regulator (The Finnish-German APECED Consortium 1997; Nagamine et al. 1997).

The AIRE gene encodes a nuclear factor of un-

${ }^{5}$ Corresponding author.

E-MAIL yaspo@impimg-berlin-dahlem.mpg.de; FAX 49-30-84131380. known function that harbors two PHD zinc fingers-a modular domain found in many proteins involved in chromatin-mediated regulation of transcription (Schindler et al. 1993; Aasland et al. 1995). Moreover, striking structural similarities were observed between AIRE and human Sp100/Sp140 proteins, suggesting that they derive from a common ancestor. In addition to the zinc fingers, AIRE and Sp140 also share a putative DNA-binding domain called SAND domain and a stretch of 90 amino acids in their amino-terminal region (Gibson 1998). Sp100 proteins localize to specific nuclear structures called nuclear bodies and represent a target of autoantibodies in patients with primary biliary cirrhosis (Szostecki et al. 1990).

As a first step toward investigating AIRE biochemical properties and for engineering a mouse model for APECED, we have cloned and characterized the murine AIRE homolog. Here we report comparative genomic sequence analysis of the AIRE loci and AIRE expression pattern on mouse and human histological sections.

\section{RESULTS}

\section{Identification of the Mouse Aire Gene}

We have isolated the mouse homolog of the human AIRE gene by cross-species screening of mouse genomic libraries with a human cDNA containing the complete AIRE coding sequence [B1-1pA (The Finnish-German APECED Consortium 1997), referred to here as hAIRE]. Six positive clones were isolated: one PAC (RPCIP711H2150), four P1s (ICRFP703A23152, 
A10129, G23152, and J2183), and one cosmid (MPMGc121L12287). After restriction digest with EcoRI and hybridization with hAIRE, all clones showed a similar pattern of four EcoRI fragments totaling a size of $20.6 \mathrm{~kb}$, except for P1 A10129, which showed an AIRE pattern of only $13.54 \mathrm{~kb}$ (data not shown). Hybridization with the most $5^{\prime}$ end and $3^{\prime}$ ends of the human cDNA indicated that A10129 was missing at least the first exon, whereas the five other genomic clones contained the whole Aire gene (data not shown).

\section{Comparative Genomic Sequencing and AIRE Gene Organization}

We have sequenced cosmid MPMGc121L12287 (GenBank accession no. AF073797) and deduced the mouse Aire gene structure by comparative analysis with the previously published hAIRE locus (cosmid LLNCO22G11; EMBL accession no. HSAJ9610). L12287 contained the 14 Aire exons spanning 13,276 bp from the proposed initiation codon to the termination codon. This compares with a length of $11,714 \mathrm{bp}$ for the human gene (Fig. 1). The mouse Aire intron/exon boundaries were confirmed experimentally after alignment of L12287 genomic sequence and mouse cDNA sequence (see below) using the EST:GENOME program
(Mott 1997). In both species, splice acceptor and donor sequences were found to conform to the GT-AG rule, and the intron phase is completely conserved (Table 1). The GC content of AIRE coding sequence is $61 \%$ in mouse versus $68 \%$ in human. Genomic information was analyzed by first-pass automatic annotation using the Rummage package (http:genome.imb-jena.de/ rummage.html). Features conserved between the two loci include a CpG island overlapping with AIRE first exon and a potential promoter associated with a TATA box located $200 \mathrm{bp}$ upstream of the proposed translation initiation site (Fig. 1). Two other genes were identified in the mouse cosmid, the PFKL promoter and a novel $\mathrm{C}_{2} \mathrm{H}_{2}$ zinc finger gene predicted in silico $6 \mathrm{~kb}$ proximal to AIRE on the opposite DNA strand (Fig. 1). This gene model is incomplete but shows significant EST matches (GenBank accession no. AA413561) and strong homology (78\%) with a human trapped exon previously located $60 \mathrm{~kb}$ proximal from the PFKL promoter on 21q22.3 (HC21EXc32; D86111) (Kudoh et al. 1997). PFKL is $3 \mathrm{~kb}$ telomeric to AIRE in human (Fig. 1), and data indicate that the linkage group HC21EXc32, AIRE, PFKL is conserved in human and mouse. To detect potentially conserved elements, the murine and human sequences were plotted on a dot matrix using the DOTTER program (Fig. 2a; Sonnhammer and

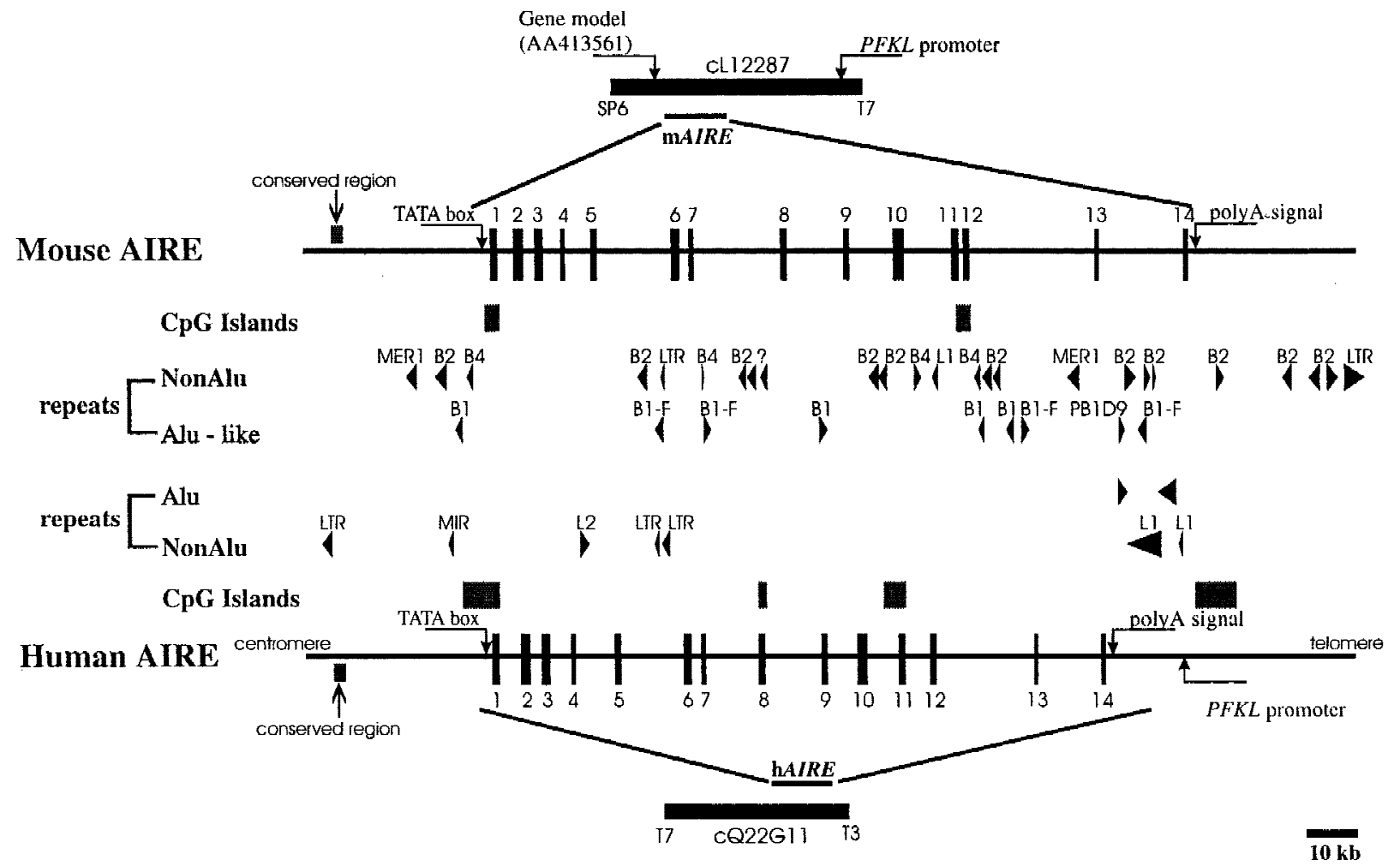

Figure 1 Comparative genomic organization of the AIRE locus. Exons are represented by solid boxes numbered from 1 to 14 . Repetitive elements are depicted by arrowheads. CpG islands are represented by solid boxes. Putative TATA box promoter and conserved region are indicated by arrows. 
Table 1. Human and Mouse Gene Structure Information

\begin{tabular}{|c|c|c|c|c|c|c|c|}
\hline $\begin{array}{l}\text { Exon } \\
\text { No. }\end{array}$ & \begin{tabular}{|l|} 
Exon \\
Size \\
(bp) \\
\end{tabular} & $\begin{array}{l}\text { Position } \\
\text { in cDNA }\end{array}$ & $\begin{array}{l}\text { Position } \\
\text { in genomic } \\
\text { DNA } \\
\end{array}$ & \begin{tabular}{|l|} 
Intron \\
size \\
(bp)
\end{tabular} & $\begin{array}{l}\text { Splice } \\
\text { Acceptor }\end{array}$ & $\begin{array}{l}\text { Splice } \\
\text { Donor }\end{array}$ & $\begin{array}{l}\text { Intron } \\
\text { phase }\end{array}$ \\
\hline \multirow[t]{2}{*}{1} & 132 & $121-252$ & $22648-22779$ & 418 & 5 UTR & CAGgtggg & 0 \\
\hline & 135 & $1-135$ & $9555-9689$ & 312 & 5 UTR & CAGgtggg & \\
\hline \multirow[t]{2}{*}{2} & 175 & $253-427$ & $23198-23372$ & 246 & tgcagGAG & AAGgtggg & 1 \\
\hline & 175 & $136-310$ & $10002-10176$ & 229 & tgcagGAG & AAGgtggg & \\
\hline \multirow[t]{2}{*}{3} & 156 & $428-583$ & $23619-23774$ & 383 & tgcagA TG & CAGgtace & 1 \\
\hline & 156 & $311-466$ & $10406-10561$ & 381 & tgcagATG & CAGgtaca & \\
\hline \multirow[t]{2}{*}{4} & 75 & $584-658$ & $24158-24232$ & 753 & ItcagGCT & ACGgtgag & 1 \\
\hline & 75 & $467-541$ & $10943-11017$ & 447 & cgcagGCT & ACGgtgag & \\
\hline \multirow[t]{2}{*}{5} & 114 & $659-772$ & $24986-25099$ & 1198 & cccagGGA & CAGgtaga & 1 \\
\hline & 114 & $542-655$ & $11465-11578$ & 1420 & tccagGAA & CAGgtaaa & \\
\hline \multirow[t]{2}{*}{6} & 146 & $773-918$ & $26298-26443$ & 185 & cccagGCG & CCẸgtang & 0 \\
\hline & 149 & $656-804$ & $12999-13147$ & 188 & cccagGAA & CCTgtaag & \\
\hline \multirow[t]{2}{*}{7} & 81 & $919-999$ & $26629-26709$ & 1026 & tgcagGGT & CAGgtaat & 0 \\
\hline & 81 & $805-885$ & $13336-13416$ & 1674 & catagGGT & CAGgtaag & \\
\hline \multirow[t]{2}{*}{8} & 116 & $1000-1115$ & $27736-27851$ & 1091 & gccagAAG & CAGgtgag & 2 \\
\hline & 116 & $886-1001$ & $15091-15206$ & 1088 & gtcagAAG & CAGgtaag & \\
\hline \multirow[t]{2}{*}{9} & 100 & $1116-1215$ & $28943-29042$ & 590 & agcagTGG & CCGgtarg & 0 \\
\hline & 100 & $1002-1101$ & $16295-16394$ & 851 & cacagTGG & CCGgtagt & \\
\hline \multirow[t]{2}{*}{10} & 183 & $1216-1398$ & $29633-29815$ & 612 & tccagCTC & CAGgtgag & 0 \\
\hline & 177 & $1102-1278$ & $17246-17422$ & 949 & tccagATC & CCAgtgag & \\
\hline \multirow[t]{2}{*}{11} & 122 & $1399-1520$ & $30428-30549$ & 490 & cacag $A A C$ & CGGgtgag & 2 \\
\hline & 122 & $1279-1400$ & $18372-18493$ & 96 & tgcagGGT & GGGgtgag & \\
\hline \multirow[t]{2}{*}{12} & $103^{\circ}$ & $1521-1623$ & $31040-31142$ & 1879 & tgeagGAC & AAGgteag & 0 \\
\hline & 109 & $1401-1509$ & $18590-18698$ & 2491 & gacagGAC & AAGgtcag & \\
\hline \multirow[t]{2}{*}{13} & 63 & $1624-1686$ & $33022-33084$ & 1206 & tccagGAT & GAGgtaac & 0 \\
\hline & 69 & $1510-1578$ & $21190-21258$ & 1492 & tccagGTA & GAGgtaat & \\
\hline \multirow[t]{2}{*}{14} & 69 & $1687-1755$ & $34291-34359$ & & cgcagCAC & \begin{tabular}{|l|}
$\begin{array}{l}3 \\
\text { UTRR } \\
\text { after stop }\end{array}$ \\
\end{tabular} & \\
\hline & 78 & $1579-1656$ & $22751-22828$ & & ctcagCAC & $\begin{array}{l}\text { 3' UTR } \\
\text { after stop }\end{array}$ & \\
\hline
\end{tabular}

Numbering of exon 1 begins from the translation start site (A of ATG start codon is position 1). Numbering of exon 14 ends at the stop codon. Nucleotide residues in the cDNA and genomic sequences refer to GenBank accession nos. Z97990 and HSAJ9610 for hAIRE and accession nos. AJ132243 and AF073307 for mouse Aire. The top and bottom lines for each exon refer to the human and mouse gene, respectively.

and Chromosome 10 DNAs (Fig. 3), in agreement with the expected conserved synteny in this region around the Pfkl locus (Irving et al. 1994).

\section{The Predicted Mouse Aire Protein}

Genomic information allowed in silico characterization of the murine cDNA sequence and corresponding conceptual protein. Nucleotide sequence identity between mouse and human AIRE coding sequences is $77 \%$. hAIRE encodes a 545-aminoacid protein. The predicted mouse Aire protein is 552 residues with a calculated pI of 8.43 and a theoretical molecular mass of $59 \mathrm{kD}$. The overall identity between the mouse and human AIRE proteins is $73 \%$ and similarity is $76 \%$ (Fig. 4). The two proteins appear remarkably conserved and harbor the same modular domains: a SAND domain, two PHD zinc fingers, a LXXLL motif, which is a signature for nuclear receptor binding site (Heery et al. 1997), and a nuclear targeting signal (Fig. 4).

\section{AIRE Gene Expression}

Using primers designed from genomic sequence information, mouse Aire cDNA fragments were isolated by PCR amplification of a cDNA source prepared from ES cells. A cDNA se-

Durbin 1995). Most of the exons were identified, albeit exons 4,7 , and 10 are barely distinguishable because of to their shorter size (exons 4 and 7) or sequence divergence. Interestingly, a highly conserved region of 90 nucleotides was identified $3 \mathrm{~kb}$ upstream of the AIRE first exon, displaying a stretch of 40 nucleotides with $80 \%$ identity (Fig. 2A,B). This region sharing no homology with other known regulatory elements may have a role in modulating AIRE expression, but this hyppothesis has to be formally demonstrated.

\section{Localization of Aire to Chromosome 10}

Comparative mapping between mouse and human has shown that human chromosome 21q22.3 shares conserved synteny with mouse Chromosomes 10 and 17 (Irving et al. 1994). The chromosomal localization of Aire was determined by PCR analysis of monochromosomal hybrids containing mouse Chromosome 10 or 17. The primer set Mforw2/Mrev32 amplified a specific product of the expected size in total mouse genome quence of 2015 bp deduced from overlapping PCR products contained an open reading frame (ORF) of 1656 bp (GenBank accession no. AJ132243). Northern blot analysis using a PCR product spanning exons 1-7 failed to detect any transcripts in the panel of mouse tissues analyzed containing heart, brain, spleen, lung, liver, skeletal muscle, kidney, and testis, indicating that Aire is seldom expressed in these tissues (data not shown). The screening of EST databases using BLAST (Altschul et al. 1990) identified only one partially processed cDNA from a 4-week mouse thymus (GenBank accession no. AA866822).

RT-PCR amplification was performed on a panel of mouse normalized first-strand cDNAs. Sequencing of cloned PCR products indicated the presence of Aire transcripts at $11 \mathrm{dpc}$ and in adult heart, spleen, lung, skeletal muscle, and testis. Three potentially functional alternatively spliced transcripts (type I, II, and III) were seen in some tissues (Table 2). Type I isoform corresponds to the skipping of exon 10 (Fig. 5A). Type II splice variant shows a 3-bp deletion at the splice ac-

160 Genome Research 


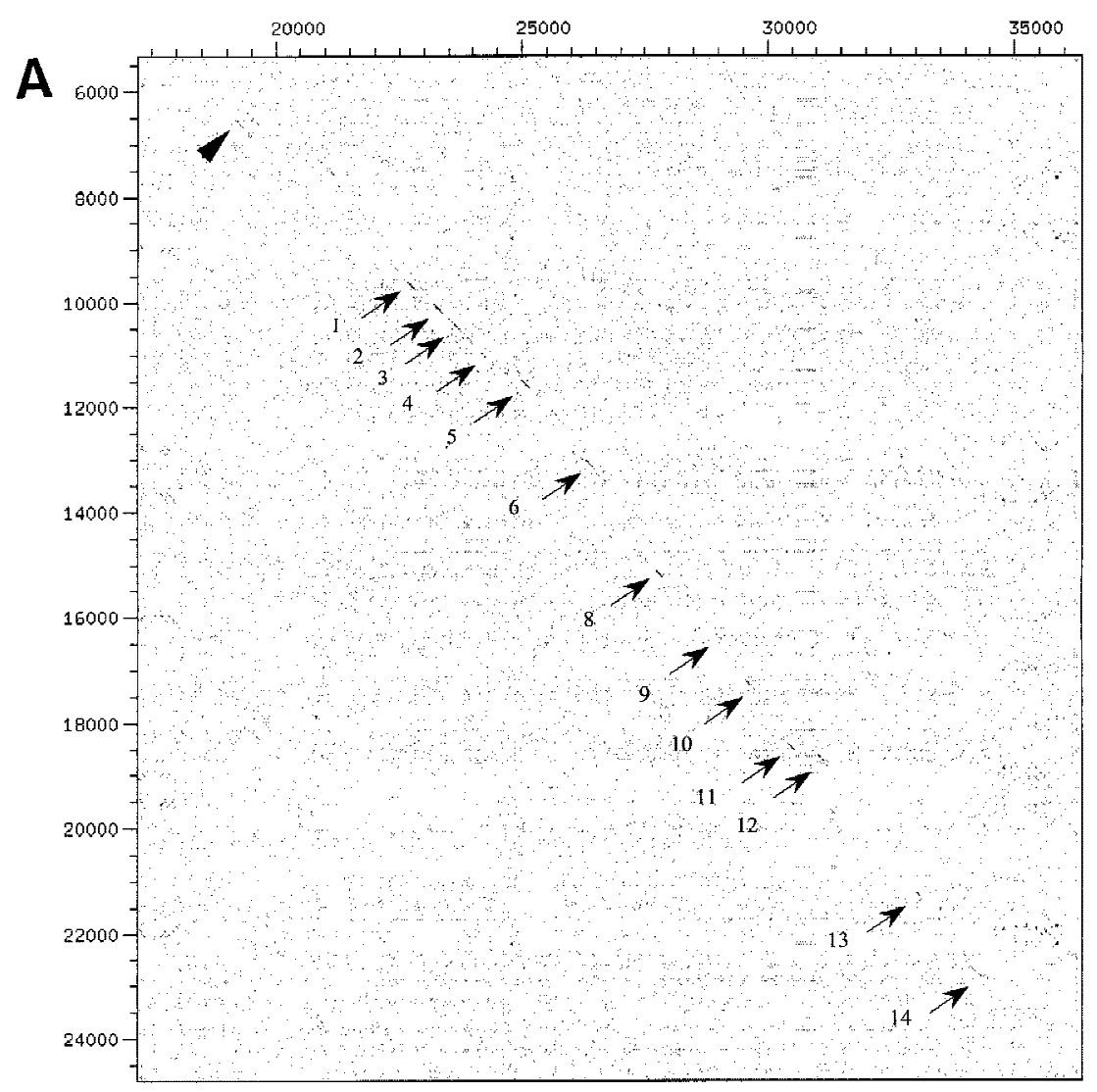

B

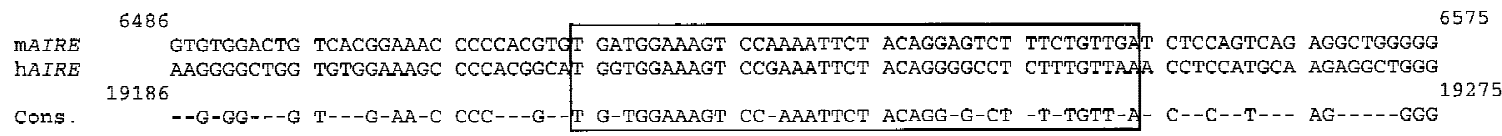

Figure $2(A)$ Dot-matrix comparative analysis of hAIRE and mouse Aire genomic sequences: HSAJ9610 is represented on the $x$-axis and AF073797 on the $y$-axis. Arrows denote exons; the arrowhead points to a conserved region located $\sim 3 \mathrm{~kb}$ upstream of the gene. (B) Alignment of the conserved nucleotide sequence identified in $A$. Numbers at the end of lines indicate nucleotide positions. Consensus sequence is drawn below the alignment. Box corresponds to the core conserved sequence.

ceptor site in exon 8 (Fig. 5B), leading to a predicted protein lacking Lys-296. Type III isoform has an inframe 12-bp deletion at exon 6 splice donor site, and

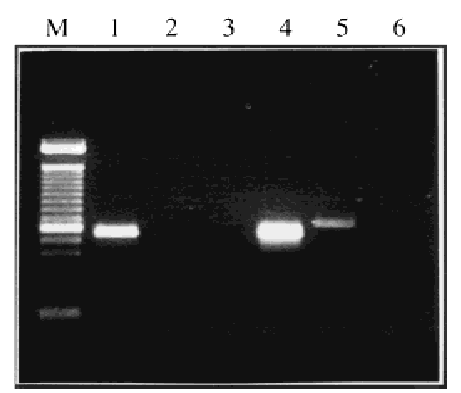

Figure 3 Mapping of Aire to mouse Chromosome 10. Electrophoresis of PCR amplification of mouse DNAs with primers Mforw2 and Mrev32.(Lane 1) Hybrid SN17C3 (Chr. 10), (Lane 2) SN11CS3 (chr. 3); (Lane 3) EJ167 (chr. 3+17); (Lane 4) mouse genomic DNA; (Lane 5) human genomic DNA; (Lane 6) no DNA. (M) 100-bp ladder (Life Technologies). the putative peptide is lacking Val-265, Thr-266, Ile267, and Pro-268 (Fig. 5C). No Aire transcripts could be obtained from $7 \mathrm{dpc}, 17 \mathrm{dpc}$, or from adult brain or kidney. Control Hprt gene PCR amplification led to a single product of comparable intensity in all tissues from the panel (not shown). In human, direct sequencing of uncloned RT-PCR products generated from a panel of tissues (see Methods) identified the type II transcript in spleen and bone marrow (data not shown). However, our data did not address whether type I and type III isoforms were conserved.

Spatial AIRE distribution was investigated by in situ hybridization on histological sections. In mouse embryo, Aire could be detected from $14.5 \mathrm{dpc}$, in which a peculiar pattern of expression was confined to a few cells in the developing thymus (Fig. 6). The cells expressing Aire are located in the medulla of the organ anlage but cannot be correlated with a particular cell type. This restricted staining pattern could either re- 


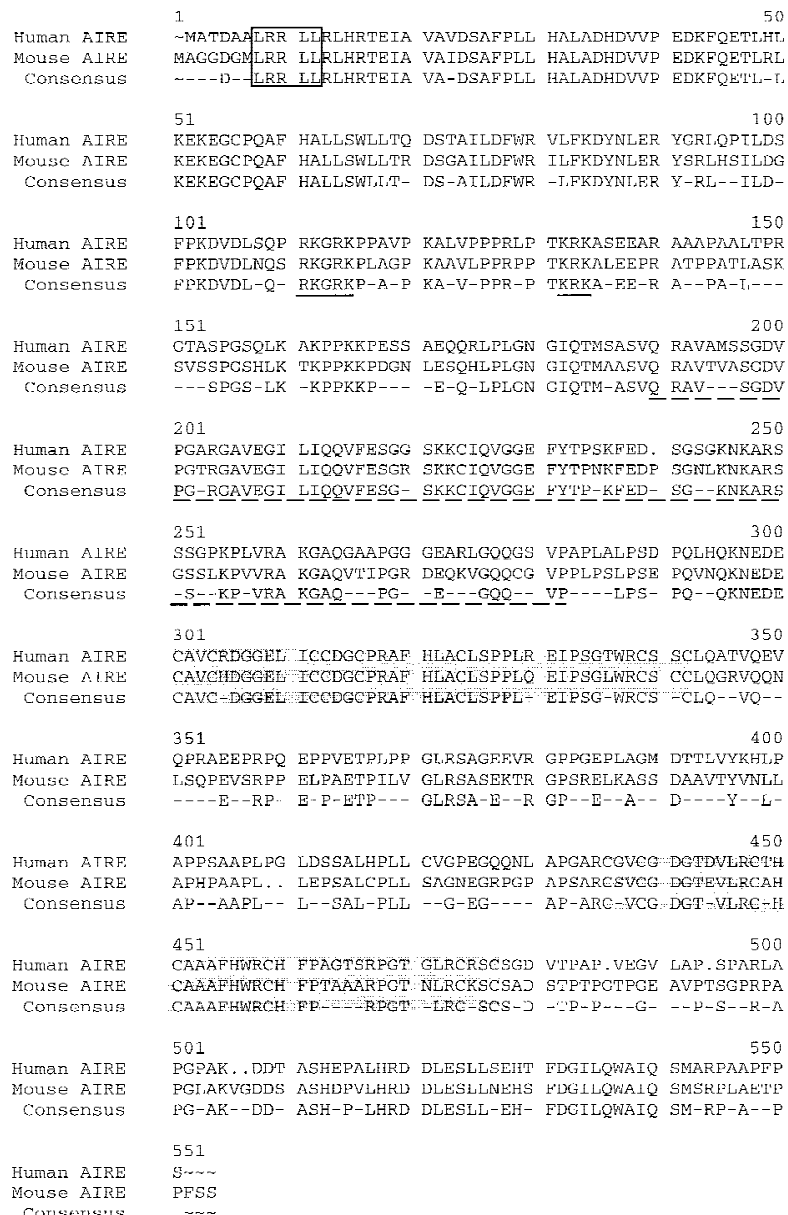

1. MATDAZZLRR LIRLHRTEIA VAVDSAFPLL HAERDHDVVP EDKEQETL.HT MAGGDGMLRR LIRLHRTEIA VAIDSAFPLL HALADDHDVV EDKFQETLRI --1D- LRR LIRLHRTEIA VA-DSAFPLL HALAADHDWP EDKEQH'TLI-T KEKEGCPQAF HALLSWLLTQ DSTAILDFWR VLEKDYNLER YGRLQPTLDS

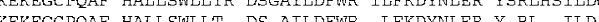

$101 \quad 150$ FPKDVDLNOS RKGRK.PL $\Lambda$ GP KRAVILPPRPP TKRK $\lambda$ LEEPR $N$ TPPATI.ASK FPRDVDL-Q- RKGRKP-A-P KA-V-PPR-P TKRKA-EE-K A-PA-T,--

151
GTASPGSQLK TIKPEKKPESS AEQQRLPLGN GIQTMISASVQ RAVAMSSGDV SVESPCSHLK TKPPKKPDGN LESQHLPLGN GIQTMANSVQ RAVTVASGDV --SPGS-LK -KPPKKP--- -E-Q-LPLGN GIQTM-ASVQ RAV---SGDV

201

201250 PGTRGAUT LIQQVFESGG SKRCIQVGG FYTPSKFED. SGSGKNRARS PGTRGAVEGI LIOOVFESGR SRKCIOVGGE FYTPNNFDP SGNLKNKARS

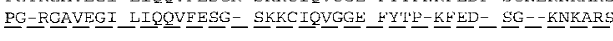
2512300 SSGPKPLVRA KGAOGAAPGG GEARLGOOGC VPAPLALPSD POLHOKNEDE GSSLKPUNA KGAQVIIPGR DEQKVGQCG VPPLPSLPSE PQVNQRNEDE

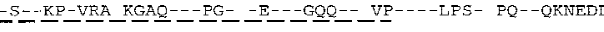
$\begin{array}{rr}301 & 350 \\ \text { CAVCRDGGEL ICCDGCPRAF HLACISPPLR EIPSGTWRCS SCLQATVQVV }\end{array}$ CAVC̈HEGGER ICCDGCPRAF HEACL SPPLO ETPSGLWRCS CCLOGRVOON CAVC-PGGEL ICCDGCPRAF HEACISPPL- EIPSG-WRCS-CLO-VO-

351 400 LSOPEVARPP ELPAETPILV GLRGAGEKTR GPSRELKASG DAAVTYYNLL

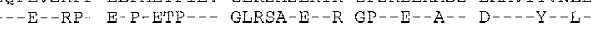
$\begin{array}{lr}401 & 450 \\ \text { A.PPSAAPEPG LDSSALHPLL CUGPEGRONL APGARCGVCG DGTPVURETH }\end{array}$

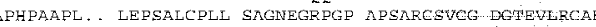
AP--AAPL-- L--GAL-PLL --G-EG---- AF-ARC-VCG DGT-VLRC-H 451

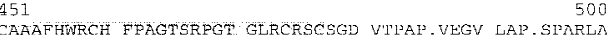

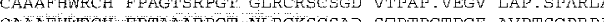
CAMTAF

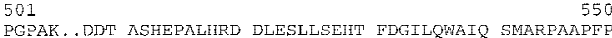

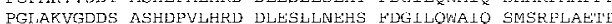
PG-AR-DD- ASH-P-LHRD DLESLL-EH- FDCILQWAIQ SM-RP-A--P

Figure 4 Amino acid aligment of hAIRE and mouse AIRE proteins. The LXXLL motif is shown by an open box; the nuclear localization signal is underlined; the SAND domain is shown by a broken line. Shaded boxes indicate the PHD zinc fingers.

flect Aire expression in only a very limited subset of cells or for a very short period of time in a larger cell population. In human, the spatial expression profile was found comparable with a signal restricted to foci of cells in the lobule of juvenile thymus medulla (Fig. 7).

\section{DISCUSSION}

We present here the cloning and characterization of the mouse ortholog of human AIRE, the gene causative for APECED disease. Comparative genomic sequencing indicated that the gene organization was highly conserved in human and mouse featuring 14 exons spanning $13 \mathrm{~kb}$ of genomic DNA, a TATA box promoter associated with a CpG island, and a potential controller element located $3 \mathrm{~kb}$ upstream of the first exon. The mouse and human AIRE genes are highly homologous at both the nucleotide and amino acid levels, and the two proteins contain similar structural hallmarks. By virtue of two PHD zinc fingers shared by a number of chromatin-associated transcriptional regulators, it was postulated that AIRE may have a role in gene regulation. PHD fingers are often found together with other functional domains, such as a RING zinc finger in KRIP-1 (Kim et al. 1996) or a helicase domain in the Mi2 autoantigen identified in some dermatomyositis patients (Ge et al. 1995; Seelig et al. 1995). AIRE's closest structural homolog is Sp100, which localizes to discrete nuclear dots (Grotzinger et al. 1996; Zuchner et al. 1997). hAIRE protein localizes to speckled domains in the cell nucleus (Rinderle et al. 1999), and its murine counterpart probably exhibits a similar subcellular localization. However, AIRE function is as yet elusive even if it provides the third example of a PHD finger protein involved in autoimmunity.

It is of paramount importance to determine the temporal and spatial distribution of AIRE for gaining insights into its primary function. Controversy revolved around the expression of human AIRE assessed previously by Northern blot. We reported AIRE expression as a $2-\mathrm{kb}$ cDNA in a range of tissues with most prevalent expression in thymus, pancreas, and adrenal cortex, using a probe spanning exons $2-5$ or with the

Table 2. Summary of the Sequenced RT-PCR Products

\begin{tabular}{|c|c|c|c|c|c|c|c|}
\hline \multirow[b]{2}{*}{ Tissue } & \multirow{2}{*}{$\begin{array}{c}\text { No. of } \\
\text { clones } \\
\text { sequenced }\end{array}$} & \multirow{2}{*}{$\begin{array}{l}\text { No. of } \\
\text { AIRE } \\
\text { sequences }\end{array}$} & \multirow[b]{2}{*}{ Canonical } & \multicolumn{3}{|c|}{ Type } & \multirow{2}{*}{$\begin{array}{l}\text { Other } \\
\text { forms }\end{array}$} \\
\hline & & & & I & II & III & \\
\hline $11 \mathrm{dpc}$ & 6 & $6 / 6$ & 3 & & & 1 & 2 \\
\hline $17 \mathrm{dpc}$ & 5 & 0 & - & - & - & - & - \\
\hline Heart & 10 & $1 / 10$ & & & & 1 & \\
\hline Spleen & 6 & $5 / 5$ & 1 & & & 1 & 3 \\
\hline Lung & 9 & $6 / 9$ & 5 & & & & 1 \\
\hline Testis & 7 & $2 / 7$ & & & 1 & 1 & \\
\hline Sk. muscle & 7 & $1 / 7$ & 1 & & & & \\
\hline Brain & 4 & 0 & - & - & - & - & - \\
\hline ES cells & 20 & $19 / 20$ & 5 & 3 & 2 & & 9 \\
\hline
\end{tabular}

Type I, II, and III isoforms are described in the left. Other forms refer to transcripts processed incompletely.

\section{Genome Research}



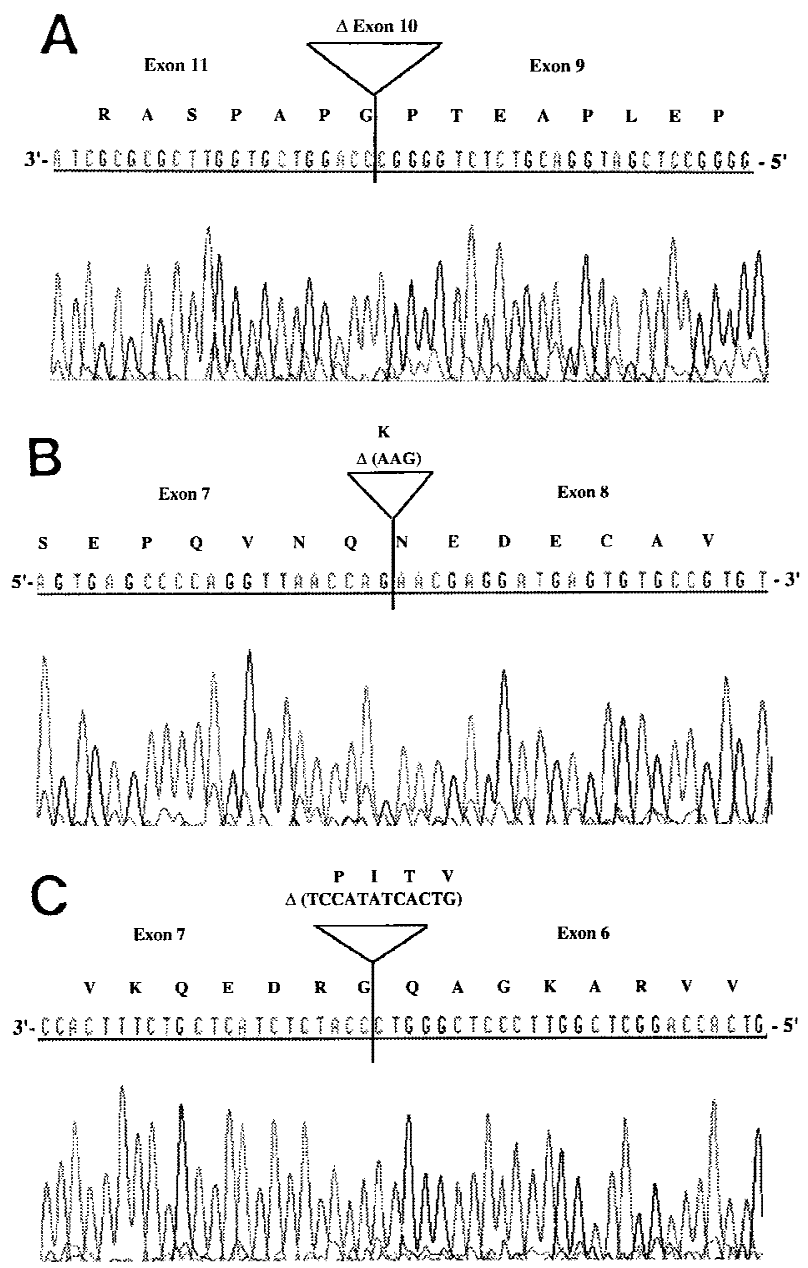

Figure 5 Differential splicing of Aire transcripts. $(A)$ Deletion of exon 10 . Sequence is reversed as indicated $3^{\prime} \rightarrow 5^{\prime} ;(B)$ deletion of 3 nucleotides at the start of exon 8; (C) deletion of 12 nucleotides at the end of exon 6 . Sequence is reversed as indicated $3^{\prime} \rightarrow 5^{\prime}$.

whole cDNA (The Finnish-German APECED Consortium 1997). However, we identified a strong 2.4-kb signal in fetal liver but not in other tissues, using a probe spanning exons 11-13 (M.L. Yaspo, unpubl.). Nagamine et al. (1997) reported a cDNA of $2.4 \mathrm{~kb}$ in fetal liver, and several transcripts of 2,3 , and $4 \mathrm{~kb}$ in lymph node and thymus, using a probe spanning exons 1214. The difference between these results can be explained in part by GC-rich regions found in the $5^{\prime}$ end of the probe, which may hybridize with nonlegitimate transcripts. In mouse, Northern blot analysis failed to detect Aire in the tissues analyzed, indicating a rare or restricted expression profile. In human, AIRE protein expression investigated by Western blot analysis failed to detect the gene product in a range of fetal and adult tissues that included organs affected in APECED, such as thyroid and parathyroid (M.L. Yaspo et al. unpubl.) Although we (M.L. Yaspo et al. unpubl.) and others (Nagamine et al. 1997) detected AIRE mRNA expres- sion in human fetal liver, this could not be confirmed by Western blot. Correlation may be difficult to draw from different samples if the gene product is expressed during a short period of time and/or at a particular developmental stage. Interestingly, in situ hybridization performed at $14.5 \mathrm{dpc}$ in the mouse indicated that Aire is expressed in only a few cells of the thymus, which are probably located in the medulla. Analysis of histological sections originating from human juvenile thymus corroborate this observation. Taken together, data confirm that AIRE is seldom expressed in most tissues. In situ hybridization data would explain the RT-PCR negative results at $17 \mathrm{dpc}$ on whole mouse embryo, considering the very low proportion of cells expressing the gene. RT-PCR analysis detected three potentially functional isoforms. These variants occur with a relatively high frequency in independent PCR reactions and are unlikely to represent artifacts. Isoform type I would lead to an in-frame deletion of 59 residues between the two PHD fingers. Examples of such splice variants in zinc finger proteins have been reported previously. For instance, alternate splicing isoforms of WT1 occurring in the hinge region spacing two Krüppel zinc fingers are associated with differential subnuclear localization (Larsson et al. 1995). However, the significance of Aire isoforms remains to be addressed formally, sensitivity of RT-PCR may reflect residual activity of a "leaky" promoter rather than true physiological expression. In situ analysis of the expression pattern on histological sections appears to be the most informative approach for tackling the temporal and spatial AIRE expression pattern. Identification of those cells expressing AIRE in the thymus will be of fundamental relevance for shedding light onto some of the pathological mechanisms leading to autoimmunity.

Mutations in AIRE represent the primary genetic defect leading to APECED, presumably because of a defective AIRE protein. AIRE expression profile in embryo and adult tissues suggest that if proven to act as a mediator of transcription, AIRE is not a global transcription factor but rather is involved in modulating the expression of tissue-specific genes, for example, in the thymus. Highly conserved protein structure and similar spatial expression profile in the thymus argue for a comparable function of AIRE in human and mouse. Characterization of the Aire murine ortholog will thus provide a tool for exploring AIRE function and for engineering a murine model of APECED

\section{METHODS}

\section{Isolation of Mouse Aire Genomic Clones}

Mouse clones were screened by hybridization of mouse genomic libraries with a human cDNA probe containing the complete AIRE coding sequence. Six positive mouse clones were isolated: PAC RPCIP711H2150 (129/SvevTACfBr); P1 


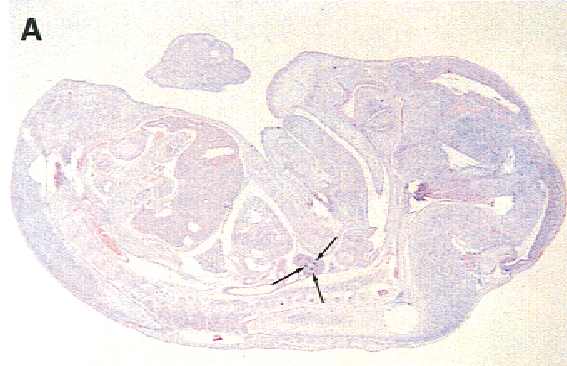

B

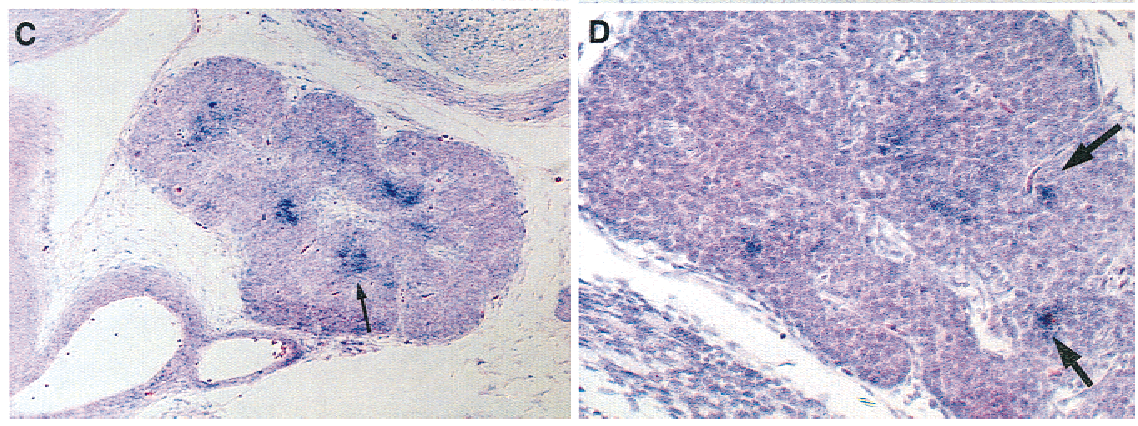

Figure 6 Expression of Aire at $14.5 \mathrm{dpc}$ is restricted to few cells in the thymus. RNA in situ hybridization with Aire antisense riboprobe recognizing exons 1-7. No signal was detected upon hybridization with a sense probe. (A) Sagittal section through $14.5 \mathrm{dpc}$. mouse embryo, counterstained with eosin. (B) Transverse section of thymic lobes of a $14.5 \mathrm{dpc}$. embryo. (C) Sagittal section of $14.5 \mathrm{dpc}$. thymus, counterstained with eosin. (D) Sagittal section of 14.5 dpc. thymus, counterstained with hematoxylin and eosin, at higher magnification. Arrows point to single cells or cell groups expressing Aire.

clones ICRFP703A23152, A10129, G23152, and J2183 (C57/ Black6); and cosmid MPMGc121L12287 (129/Ola).

\section{Genomic Sequencing}

Cosmid DNAs were isolated using a standard lysis method and purified on a $\mathrm{CsCl}$ gradient. DNA was sonicated, size fractionated, and ligated into M13 vector for shotgun sequencing using Thermo Sequenase (Amersham) and dye-terminator chemistry (Perkin Elmer). Data were collected using ABI 377 automated sequencers and assembled with Gap4 (Staden 1996). Gaps were closed by resequencing the M13 templates with ET (Energy Transfer) dye primers (Amersham).

\section{Computer Analysis}

Repeats were identified with the Repeat masker program http://ftp.genome.washington.edu/RM/RepeatMasker.html); (A.F.A Smit and P. Green). Homology searches were performed using BLAST version 1.4 (Altschul et al. 1990) and FASTA version 2.0 (Pearson and Lipman 1988). Programs GRAIL2 (Uberbacher and Mural 1991), XPOUND (Thomas and Skolnick 1994), MZEF (Zhang 1997), and GENSCAN (Burge and Karlin 1997) were used for exon prediction. Promoter predictions were done with Promoter Scan II (Prestridge 1995) and Transcription Start Site using both Ghosh/ Prestridge (TSSG) and Wigender (TSSW) motif databases (http://dot.imgen.bcm.tmc.edu:9331/gene-finder/gf.html); (V.V. Solovyev, A.A. Salamov, and C.B. Lawrence). Dot matrix comparison was performed on a DEC- $\alpha$ station using the DOTTER program (Sonnhammer and Durbin 1995), and analysis was done using set default parameters.

\section{RNA and RT-PCR analysis}

\section{Analysis of Mouse Aire}

A Northern blot containing $2 \mathrm{mg}$ of poly $(\mathrm{A})^{+}$RNA was purchased from Clontech. RT-PCR analysis was performed on ES cells cDNA and on a normalized first-strand cDNA panel from mouse multiple tissues (Clontech). Primers Mforw4 (5'-TGGCAGGTGGGGATGGAA-3') and Mrev15 (5'-GGAGGGATGGAAGGGGAGGA$3^{\prime}$ ) amplified a product spanning exons 1-7. PCR reactions were performed in a Biometra UNO II thermocycler. An initial denaturation at $94^{\circ} \mathrm{C}$ for 2 min was followed by 35 cycles at $94^{\circ} \mathrm{C}$ for $45 \mathrm{sec}, 56^{\circ} \mathrm{C}$ for 40 sec, $72^{\circ} \mathrm{C}$ for $1 \mathrm{~min}$, and a final extension at $72^{\circ} \mathrm{C}$ for $5 \mathrm{~min}$. Primers Mforw6 (5'-AAAGCCAGTGGTCCGAGCCAA-3') and Mrev34. (5'GGAAGTGGCAGCGCCAGT-3') amplified exons 6-11. Primers Mforw7 (5'-TGGTCCGAGCCAAGGGAG-3') and MR4 (5'-GCCACCTGTCATCAGGAAGAG-3') were used to amplify a cDNA fragment spanning exon 7-14 and extending in the $3^{\prime}$ direction outside of the translated region. Conditions for all PCRs were basically identical with the exception of the annealing temperature specific for each primer pair.

\section{Analysis of hAIRE}

RT-PCR analysis was performed on a normalized first-strand cDNA panel from human immune system tissue (Clontech). Primers B127FR4-21 (5'-GGCTTCTGAGGCTGCACC-3') and B127FR4-29 (5'-GCTCTGGATGGCCTACTG C-3') were used to amplify a $1.6-\mathrm{kb}$ fragment. Nested PCRs were performed using primers B127FR4-17 (5'-AGAAGTGCATCCAGGTTGGC-3') and B127FR4-33 (5'-GTGTGCTCGCTCAGAAGGG$\left.3^{\prime}\right)$ and products were sequenced directly.

\section{Sequencing of PCR Products}

Products from PCR amplifications were purified using the QIAquick PCR Purification Kit (Qiagen). Purified products were sequenced using the dye-terminator chemistry on an ABI 377 automated sequencer (Perkin Elmer).

\section{Chromosomal Localization of Aire}

PCR amplifications were performed using mouse-specific primers Mforw2 (5'-TCCCACCTGAAGACTAAGC-3') and Mrev32 (5'-TCACAGCTC TCTGGACAGAA-3') on hybrids SN11CS3 and SN17C3 containing mouse chromosome 3 and 10, respectively (Sabile et al. 1997) and hybrid EJ167 containing mouse chromosomes 17 and 3 (Cox et al. 1991). PCR reactions were performed in a Biometra UNO II thermocycler. Initial denaturation at $94^{\circ} \mathrm{C}$ for 2 min was followed by 35 cycles at $94^{\circ} \mathrm{C}$ for $45 \mathrm{sec}, 51^{\circ} \mathrm{C}$ for $40 \mathrm{sec}, 72^{\circ} \mathrm{C}$ for $2 \mathrm{~min}$, and a final extension at $72^{\circ} \mathrm{C}$ for $5 \mathrm{~min}$.

\section{Genome Research}



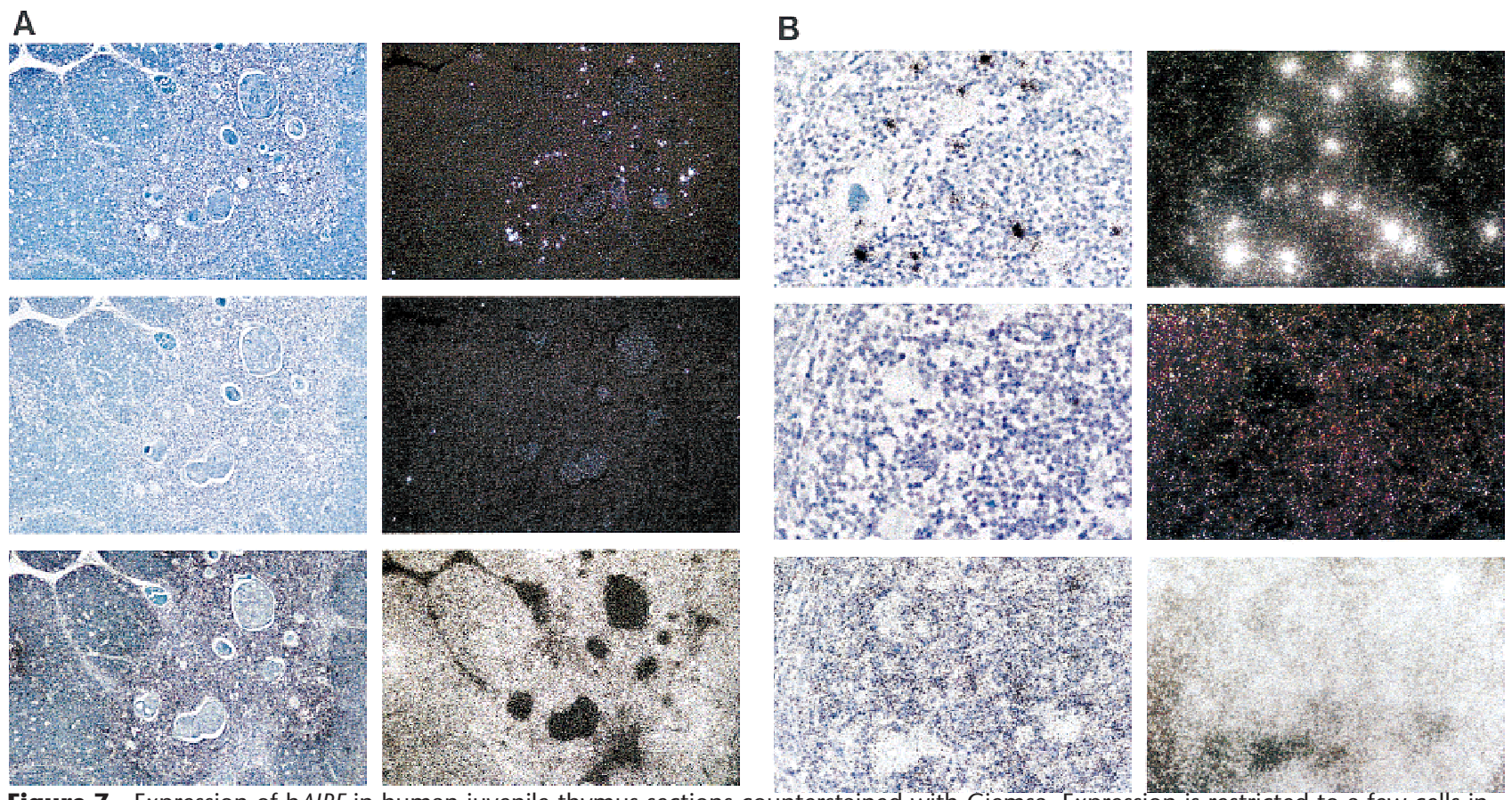

Figure 7 Expression of hAIRE in human juvenile thymus sections counterstained with Giemsa. Expression is restricted to a few cells in the medulla of the thymic lobule. (Top) The antisense probe; (middle) the sense probe; (bottom) the control $\beta$-actin probe. (Left) Bright field; (right) dark field. (A) Magnification, $100 \times ;(B)$ another section with magnification, $500 \times$.

\section{In Situ Hybridization}

In situ hybridization on mouse sections was performed essentially according to Henry et al. (1996). The cloned RT-PCR product used for riboprobe synthesis recognizes all splice variants and spans exons $1-7$. Hybridization stringency was $5 \times$ SSC, $50 \%$ formamide, at $65^{\circ} \mathrm{C}$. Final washing stringency was $1 \times \mathrm{SSPE}, 50 \%$ formamide, at $50^{\circ} \mathrm{C}$. The sections were stained for 2-3 days with BM-Purple (Boehringer). Counterstaining with eosin or with hematoxylin and eosin was performed according to standard procedures. In situ hybridization on human sections was performed with ${ }^{35} \mathrm{~S}$ radiolabeled riboprobe spanning human exons 7-14 (sense and antisense), using a standard protocol described previously (Poulsom et al. 1988; Senior et al. 1988;). Sections were $4 \mu \mathrm{m}$ thick from formaline, paraffin-embedded samples. Final washing stringency was $0.5 \times \mathrm{SSC}$ at $65^{\circ} \mathrm{C}$. Counterstaining with Giemsa was performed according to standard procedures. Exposure was for 31 days for AIRE and 10 days for $\beta$-actin control.

\section{ACKNOWLEDGMENTS}

We thank the Resource Center Team (RZPD) for providing mouse library filters and genomic clones. We thank Dr. Tilman Vogel (UniKlinik, Duesseldorf) for providing tissue samples. We thank Dr. Heinz Himmelbauer for the mouse monochromosomal hybrid DNAs and Dr. Michael Wiles for providing ES cell first-strand cDNA. Margit Teuchtler and Bärbel Ukena are appreciated for excellent technical assistance. This work was supported by the Deutsche Human Genome Projekt (grants BMBF 01KW9608 and 01KW9617).

The publication costs of this article were defrayed in part by payment of page charges. This article must therefore be hereby marked "advertisement" in accordance with 18 USC section 1734 solely to indicate this fact.

\section{REFERENCES}

Aaltonen, J., P. Bjorses, L. Sandkuijl, J. Perheentupa, and L. Peltonen. 1994. An autosomal locus causing autoimmune disease: Autoimmune polyglandular disease type I assigned to chromosome 21. Nat. Genet. 8: 83-87.

Aasland, R., T.J. Gibson, and A.F. Stewart. 1995. The PHD finger: Implications for chromatin-mediated transcriptional regulation. Trends Biochem. Sci. 20: 56-59.

Ahonen, P. 1985. Autoimmune polyendocrinopathy-candidosis-ectodermal dystrophy (APECED): Autosomal recessive inheritance. Clin. Gen. 27: 535-542.

Ahonen, P., S. Myllarniemi, I. Sipila, and J. Perheentupa. 1990. Clinical variation of autoimmune polyendocrinopathy-candidiasis-ectodermal dystrophy (APECED) in a series of 68 patients. N. Engl. J. Med. 322: 1829-1836.

Altschul, S.F., W. Gish, W. Miller, E.W. Myers, and D.J. Lipman. 1990. Basic local alignment search tool. J. Mol. Biol. 215: 403-410.

Bjorses, P., J. Aaltonen, A. Vikman, J. Perheentupa, G. Benzion, G Chiumello, P. Heideman, J.J.G. Hoorwegnijman, L. Mathivon, P.E. Mullis et al. 1996. Genetic homogeneity of autoimmune polyglandular disease type I. Am. J. Hum. Genet. 59: 879-886.

Burge, C. and S. Karlin. 1997. Prediction of complete gene structures in human genomic DNA. J. Mol. Biol. 268: 78-94.

Clemente, M.G., P. Obermayer-Straub, A. Meloni, C.P. Strassburg, V. Arangino, R.H. Tukey, S. De Virgiliis, and M.P. Manns. 1997. Cytochrome P450 1A2 is a hepatic autoantigen in autoimmune polyglandular syndrome type 1. J. Clin. Endocrinol. Metab. 82: $1353-1361$.

Cox, R.D., L. Stubbs, T. Evans, and H. Lehrach. 1991. A mouse specific polymerase chain reaction (PCR) primer: Probe generation from somatic cell hybrids. Nucleic Acids Res. 19: 2503.

The Finnish-German APECED Consortium. 1997. An autoimmune disease, APECED, caused by mutations in a novel gene featuring two PHD-type zinc-finger domains. Autoimmune 
Polyendocrinopathy-Candidiasis-Ectodermal Dystrophy. Nat. Genet. 17: 399-403.

Ge, Q., D.S. Nilasena, C.A. O'Brien, M.B. Frank, and I.N. Targoff. 1995. Molecular analysis of a major antigenic region of the 240-kD protein of Mi-2 autoantigen. J. Clin. Invest. 96: $1730-1737$.

Gibson, T.J., C. Ramu, C. Gemünd, and R. Aasland. 1998. The APECED polyglandular autoimmune syndrome protein, AIRE-1, contains the SAND domain and is probably a transcription factor. Trends Biol. Sci. 23: 242-244.

Grotzinger, T., T. Sternsdorf, K. Jensen, and H. Will. 1996. Interferon-modulated expression of genes encoding the nuclear-dot-associated proteins Sp100 and promyelocytic leukemia protein (PML). Eur. J. Biochem. 238: 554-560.

Heery, D.M., E. Kalkhoven, S. Hoare, and M.G. Parker. 1997. A signature motif in transcriptional co-activators mediates binding to nuclear receptors. Nature 387: 733-736.

Henry, G.L., I.H. Brivanlou, D.S. Kessler, A. Hemmati-Brivanlou, and D.A. Melton. 1996. TGF-beta signals and a pattern in Xenopus laevis endodermal development. Development 122: 1007-1015.

Irving, N.G., D.E. Cabin, D.A. Swanson, and R.H. Reeves. 1994. Gene order is conserved within the human chromosome 21 linkage group on mouse chromosome 10. Genomics 21: 144-149.

Kim, S.S., Y.M. Chen, E. O'Leary, R. Witzgall, M. Vidal, and J.V. Bonventre 1996. A novel member of the RING finger family, KRIP-1, associates with the KRAB-A transcriptional repressor domain of zinc finger proteins. Proc. Natl. Acad. Sci. 93: $15299-15304$

Korenberg, J.R., J. Aaltonen, C. Brahe, D. Cabin, N. Creau, J.M. Delabar, J. Doering, K. Gardiner, R.S. Hubert, J. Ives et al. 1997. Report of the sixth international workshop on human chromosome 21 mapping 1996. Cytogenet. Cell. Genet. 79: 22-34.

Kudoh, J., K. Nagamine, S. Asakawa, I. Abe, K. Kawasaki, H. Maeda, S. Tsujimoto, S. Minoshima, F. Ito, and N. Shimizu. 1997. Localization of 16 exons to a $450-\mathrm{kb}$ region involved in the autoimmune polyglandular disease type I (APECED) on human chromosome 21q22.3. DNA Res. 4: 45-52.

Larsson, S.H., J.P. Charlieu, K. Miyagawa, D. Engelkamp, M. Rassoulzadegan, A. Ross, F. Cuzin, V. van Heyningen, and N.D. Hastie. 1995. Subnuclear localization of WT1 in splicing or transcription factor domains is regulated by alternative splicing. Cell 81: 391-401.

Mott, R. 1997. EST:GENOME: A program to align spliced DNA sequences to unspliced genomic DNA. Comput. Appl. Biosci. 13: $477-478$.

Nagamine, K., P. Peterson, H.S. Scott, J. Kudoh, S. Minoshima, M. Heino, K.J. Krohn, M.D. Lalioti, P.E. Mullis, S.E. Antonarakis et al. 1997. Positional cloning of the APECED gene. Nat. Genet. 17: 393-398.

Ollier, W.A.S., and D.P.M. 1992. Autoimmunity. Bioscientific Publishers, Oxford, UK.

Pearson, W.R., and D.J. Lipman. 1988. Improved tools for biological sequence comparison. Proc. Natl. Acad. Sci. 85: 2444-2448.

Perheentupa, J. 1996. Autoimmune

polyendocrinopathy-candidiasis-ectodermal dystrophy

(APECED). Hormone Metab. Res. 28: 353-356.
Poulsom, R., J.M. Longcroft, R.E. Jefferey, L.A. Rogers, and A. Steel. 1988. A robust method for isotopic in situ hybridization to localize mRNAs in routine pathology specimens. Eur. J. Histochem. 42: 121-132.

Prestridge, D.S. 1995. Predicting Pol II promoter sequences using transcription factor binding sites. J. Mol. Biol. 249: 923-932.

Rinderle, C., H-M. Christensen, S. Schweiger, H. Lehrach, and M. L. Yaspo. 1999. AIRE encodes a nuclear protein co-localizing with cytoskeletal filaments: Altered sub-cellular distribution of mutants lacking the PHD zinc fingers. Hum. Mol. Genet. (in press).

Sabile, A., I. Poras, D. Cherif, P. Goodfellow, and P. Avner. 1997. Isolation of monochromosomal hybrids for mouse chromosomes 3, 6, 10, 12, 14, and 18. Mamm. Genome 8: 81-85.

Schindler, U., H. Beckmann, and A.R. Cashmore. 1993. HAT3.1, a novel Arabidopsis homeodomain protein containing a conserved cysteine-rich region. Plant J. 4: 137-150.

Seelig, H.P., I. Moosbrugger, H. Ehrfeld, T. Fink, M. Renz, and E. Genth. 1995. The major dermatomyositis-specific Mi-2 autoantigen is a presumed helicase involved in transcriptional activation. Arthritis Rheum. 38: 1389-1399.

Senior, P.V., D.R. Critchley, F. Beck, R.A. Walker, and J.M.Varley. 1988. The localization of laminin mRNA and protein in the postimplantation embryo and placenta in the mouse: An in situ immunohistological study. Development 104: 431-446.

Sonnhammer, E.L. and R. Durbin. 1995. A dot-matrix program with dynamic threshold control suited for genomic DNA and protein sequence analysis. Gene 167: GC1-10.

Staden, R. 1996. The Staden sequence analysis package. Mol. Biotechnol. 5: 233-241.

Szostecki, C., H.H. Guldner, H.J. Netter, and H. Will. 1990. Isolation and characterization of cDNA encoding a human nuclear antigen predominantly recognized by autoantibodies from patients with primary biliary cirrhosis. J. Immunol. 145: 4338-4347.

Thomas, A., and M.H. Skolnick. 1994. A probabilistic model for detecting coding regions in DNA sequences. IMA J. Math. Appl. Med. Biol. 11: 149-160.

Uberbacher, E.C., and R.J. Mural. 1991. Locating protein-coding regions in human DNA sequences by a multiple sensor-neural network approach. Proc. Natl. Acad. Sci. 88: 11261-11265.

Zhang, M.Q. 1997. Identification of protein coding regions in the human genome by quadratic discriminant analysis [published erratum appears in Proc. Natl. Acad. Sci. 1997 94: 5495]. Proc. Natl. Acad. Sci. 94: 565-568.

Zlotogora, J. and M.S. Shapiro. 1992. Polyglandular autoimmune syndrome type I among Iranian Jews. J. Med. Genet. 29: 824-826.

Zuchner, D., T. Sternsdorf, C. Szostecki, E.J. Heathcote, K. Cauch-Dudek, and H. Will. 1997. Prevalence, kinetics, and therapeutic modulation of autoantibodies against Sp100 and promyelocytic leukemia protein in a large cohort of patients with primary biliary cirrhosis. Hepatology 26: 1123-1130.

Received October 26, 1998; accepted in revised form January 11, 1999.

166 Genome Research 


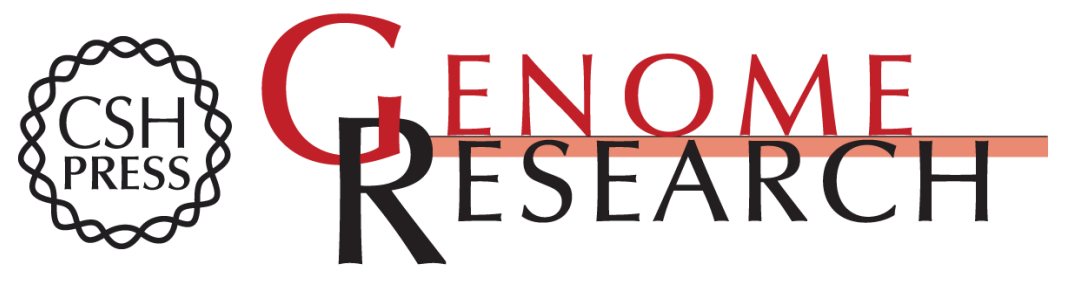

\section{The Mouse Aire Gene: Comparative Genomic Sequencing, Gene Organization, and Expression}

Karin Blechschmidt, Michal Schweiger, Karin Wertz, et al.

Genome Res. 1999 9: 158-166

Access the most recent version at doi:10.1101/gr.9.2.158

References This article cites 35 articles, 8 of which can be accessed free at:

http://genome.cshlp.org/content/9/2/158.full.html\#ref-list-1

\section{License}

Email Alerting Receive free email alerts when new articles cite this article - sign up in the box at the Service top right corner of the article or click here.

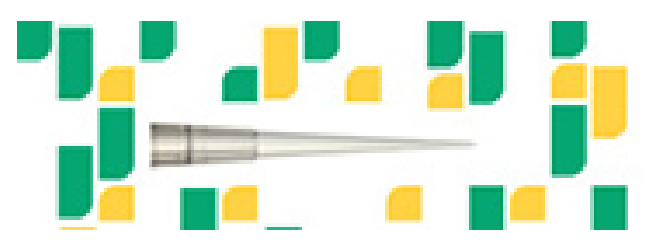

To subscribe to Genome Research go to: https://genome.cshlp.org/subscriptions 